\title{
Study on safety operation of medium voltage distribution network
}

\author{
Xiaofang Chen ${ }^{1}$, Li'an Chen $^{1, *}$, Dong Wang ${ }^{2}$, and Qihao Chen ${ }^{1}$ \\ ${ }^{1}$ Xiamen University of Technology, School of Electrical Engineering and Automation, China \\ ${ }^{2}$ State Grid Department of Safety and Quality Supervision Beijing, China
}

\begin{abstract}
Aiming at the problem of safe operation in the medium voltage distribution network with neutral point grounding through small resistance, the distribution network model was built, and on this basis, MW-level photovoltaic (PV) system, doubly fed Induction generator (DFIG) wind turbine, permanent magnet synchronous generator (PMSG) wind turbine and energy storage device was connected respectively in this paper. The ground current and earth potential rise was studied when the power was delivered by mistake. The simulation results show that in the system with neutral point grounding through small resistance, whether it is the traditional or the active distribution network, the three-phase power delivery method is more able to ensure the personal safety of power grid operators. However, The access to distributed generator (DG) in the distribution network will have a greater impact on ground current and earth potential rise in the case of three-phase power delivery. Especially when the ground current and earth potential rise will increase after DG connected to distribution network, which is still likely to pose a threat to personal safety and needs further research.
\end{abstract}

Keywords: Safe operation; PV; DFIG; PMSG; Energy storage device.

\section{Introduction}

Safe operation is a serious problem. If the power is deliveried by mistake during maintenance, the current will affect the breathing, heart and nervous system, and cause the destruction of the internal tissues of the human body, resulting in death. It is found that the ground current and earth potential rise are far greater than the safe range that the human body can withstand if the power mis-delivery occurs in the process of repairing the neutral point grounding distribution network through small resistance. Especially, more and more distributed generators (DGs) are connected to the medium voltage distribution network, which poses greater challenges to the safety operation. Though, There are many aspects in the research of active distribution network: Reference [1] proposed an expansion planning model for multi-energy system integrating active distribution network, energy hub and natural gas network ; Reference [2] proposed a procedure for the optimal siting and sizing of energy storage systems within active distribution networks hosting many stochastic distributed renewable energy resources; A capacity allocation method of energy storage

\footnotetext{
*Corresponding author: chenla@xmut.edu.cn
} 
system for active distribution network considering health risk assessment is proposed in Reference [3], few people explore the problem of safety operation.

The contribution of this paper is to study the ground current and ground potential rise when the neutral point operates through a small resistance grounding system, and give corresponding suggestions. To study the influence of DG connection on the ground current and ground potential rise is another contribution. So the traditional distribution network model is built in this paper. On this basis, the photovoltaic (PV) system, doubly fed induction generator (DFIG), permanent magnet synchronous generator (PMSG) and energy storage devices are connected. The ground current and earth potential rise under singlephase and three-phase power delivery conditions are analyzed quantitatively.

\section{Modeling of active distribution network}

The safety operation diagram of distribution network with DG through small resistance grounding mode is shown in Fig.1.

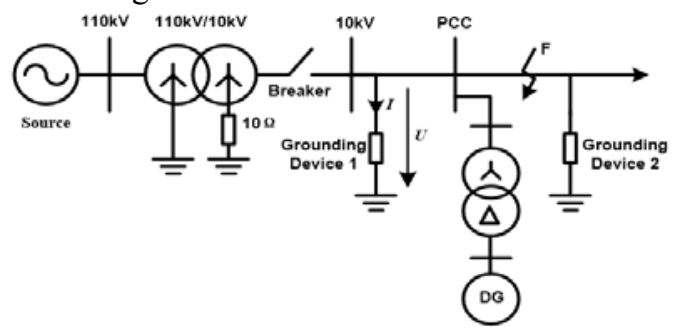

Fig. 1. The safety operation schematic diagram of distribution network with low resistance grounding including DG mode.

When the traditional power grid is studied, there is no DG module. When the active distribution network is studied, the DG module can be PV system, DFIG wind turbine, PMSG wind turbine, energy storage device, etc. PCC is the common connection point between DG and power grid. The ground current refers to the current $I$ flowing into the earth through the earth connection after the earth connection is mounted on both ends of the point $\mathrm{F}$, which is maintenance point. The earth potential rise is the potential difference between the grounding device and the reference earth when the current flows through the grounding electrode of the grounding device into the earth, which is expressed by the voltage $U$ in the figure.

\subsection{Earth connection model}

As shown in Fig.2, the earth connection is composed of resistance $r_{1}, r_{2}, r_{3}$ and $\mathrm{R}$, where $r_{1}$, $r_{2}$ and $r_{3}$ is short-circuit resistance, and $R$ is the equivalent resistance of grounding wire in series with earthing electrode. The short-circuit resistance is $0.001 \Omega$, The resistance value of $R$ is the sum of the resistance of earthing wire $R_{1}$ and earthing electrode resistance $R_{2}$. Fig. 3 is the schematic diagram of earthing electrode.

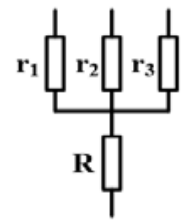

Fig. 2. Earth connection model.

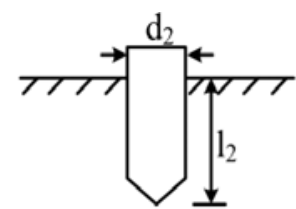

Fig. 3.Schematic diagram of earthing electrode. 
The resistance of earthing wire R1 is defined as (1)

$$
R_{1}=\rho_{1} \frac{l_{1}}{S_{1}}
$$

Where, $\rho_{1}$ is the wire resistivity, when the wire material is copper, $\rho_{1}$ is $1.75 \times 10^{-8} \Omega \cdot m, S_{1}$ is the wire cross-sectional area, which is $25 \mathrm{~mm}^{2}, l_{1}$ is the wire length, is 1.5 (the length of wires connected with phase $\mathrm{A}, \mathrm{B}$ and $\mathrm{C}$ ) +17 (the length of wires connected with earth) $\mathrm{m}$, the earthing wire resistance $\left(R_{1}\right)$ is calculated as $0.013 \Omega$.

According to the regulation on the Code for Design of AC Electrical Installations Earthing (GB/T 50065-2011), the schematic diagram of earthing electrode is shown as Fig.3, the formula of earthing electrode resistance $\left(R_{2}\right)$ is $(2)$.

$$
R_{2}=\frac{\rho_{2}}{2 \pi l_{2}}\left(\ln \frac{8 l_{2}}{d_{2}}-1\right)
$$

Where, $\rho_{2}$ is soil resistivity, the resistivity of loess in general areas or rainy areas is 100 $200 \Omega \cdot \mathrm{m}$, here is $150 \Omega \cdot \mathrm{m}, l_{2}$ is the length of earthing electrode, the value is $0.6 \mathrm{~m}, d_{2}$ is the earthing electrode diameter, when the earthing electrode material is round steel, $d_{2}$ is 0.05 $\mathrm{m}$, the earthing electrode resistance $\left(R_{2}\right)$ is calculated as $141.87 \Omega$, and the equivalent resistance of earthing wire and earthing electrode $(R)$ is $141.88 \Omega$.

\subsection{Mathematical model of distributed generation}

The mathematical model of photovoltaic power generation is shown in Fig.4, and the corresponding formula is shown in (3), The equivalent model of DFIG wind turbine in dq synchronous coordinate system is shown in Fig.5, and the corresponding formula is shown in (4).

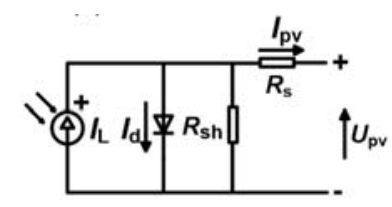

Fig. 4. Mathematical model of PV generation.

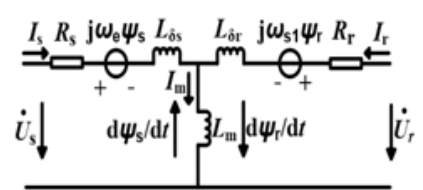

Fig. 5. The equivalent model of DFIG wind turbine in dq synchronous coordinate system.

$$
I_{\mathrm{d}}=I_{0}\left[\exp \left(\frac{U_{\mathrm{d}} \mathrm{q}}{k T N_{\mathrm{d}}-N_{\text {cell }}}\right)-1\right]
$$

Where, $I_{\mathrm{d}}$ is diode current, $U_{\mathrm{d}}$ is diode voltage, $\mathrm{q}$ is electron charge, the value is $1.6022 \times 10^{-19}, I_{0}$ is diode saturated current, $\mathrm{k}$ is Boltzmann constant, numerical value closes to 1 , T is battery temperature, $N_{\text {cell }}$ is the number of series cells in the module ${ }^{[4]}$.

$$
\left\{\begin{array}{l}
\psi_{\mathrm{s}}=L_{\mathrm{s}} I_{\mathrm{s}}+L_{\mathrm{m}} I_{\mathrm{r}} \\
\psi_{\mathrm{r}}=L_{\mathrm{r}} I_{\mathrm{r}}+L_{\mathrm{m}} I_{\mathrm{s}} \\
U_{\mathrm{s}}=R_{\mathrm{s}} I_{\mathrm{s}}+\frac{\mathrm{d} \psi_{\mathrm{s}}}{\mathrm{d} t}+\mathrm{j} \omega_{\mathrm{e}} \Psi_{\mathrm{s}} \\
U_{\mathrm{r}}=R_{\mathrm{r}} I_{\mathrm{r}}+\frac{\mathrm{d} \psi_{\mathrm{r}}}{\mathrm{d} t}+\mathrm{j} \omega_{\mathrm{s} 1} \Psi_{\mathrm{r}} \\
T_{\mathrm{e}}=\frac{3}{2} p_{\mathrm{n}} \operatorname{lm}\left[\Psi_{\mathrm{s}} \hat{I}_{\mathrm{s}}\right] \\
P_{\mathrm{s}}+\mathrm{j} Q_{\mathrm{s}}=-\frac{3}{2} U_{\mathrm{s}} \hat{I}_{\mathrm{s}}
\end{array}\right.
$$


Where, $\psi_{\mathrm{s}}, \psi_{\mathrm{r}}$ is the flux phasor of stator and rotor $, U_{\mathrm{s}}, U_{\mathrm{r}}$ is the voltage phasor of stator and rotor, $I_{\mathrm{s}}, I_{\mathrm{r}}$ is the current phasor of stator and rotor, " $\wedge$ " is presented as conjugate, $P_{\mathrm{s}}, Q_{\mathrm{s}}$ is active power and reactive power of stator, $L_{\mathrm{s}}$ is the self-inductance of the stator winding in the synchronous coordinate system, $L_{\mathrm{r}}$ is the self-inductance of the rotor winding in the synchronous coordinate system, $L_{\mathrm{m}}$ is the equivalent mutual inductance between the stator winding and the rotor winding in the synchronous coordinate system, $R_{\mathrm{s}}$ is the stator resistance, $R_{\mathrm{r}}$ is the rotor resistance, $\omega_{\mathrm{e}}$ is synchronous speed, $\omega_{\mathrm{s} 1}$ is the slip angular velocity, $p_{\mathrm{n}}$ is the polar pairs ${ }^{[5]}$.

Reference [6] expresses the equivalent model of PMSG wind turbine in dq synchronous coordinate system and the corresponding formula in detail.

Thevenin model is used to model the lithium iron phosphate battery monomer in the energy storage device as shown in Fig.6, and the mathematical model is expressed as (5).

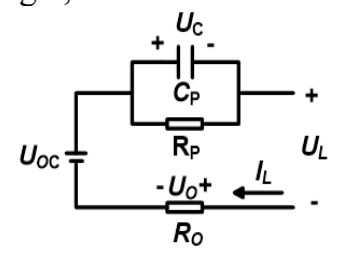

Fig. 6. Mathematical model of energy storage device.

$$
\left\{\begin{array}{l}
U_{\mathrm{L}}=U_{\mathrm{OC}}-R_{0} I_{\mathrm{L}}-U_{\mathrm{C}} \\
I_{\mathrm{L}}=C_{\mathrm{P}} \frac{d U_{\mathrm{C}}}{d t}+\frac{U_{\mathrm{C}}}{R_{\mathrm{P}}}
\end{array}\right.
$$

Where, $C_{\mathrm{p}}$ is polarization capacitor, $R_{\mathrm{p}}$ is polarization resistance, $U_{\mathrm{c}}$ is the terminal voltage of polarization capacitor, $U_{\mathrm{oc}}$ is open circuit voltage for single cell, $R_{\mathrm{o}}$ reflects the mutation characteristics of voltage, $U_{\mathrm{L}}, I_{\mathrm{L}}$ is the discharge voltage and current for single cell[ ${ }^{[7]}$.

\subsection{Grid connection strategy of distributed generation}

The grid-connected strategies of distributed generation in this paper are all based on dq transformation, and the grid-connected strategy of PV system is illustrated as an example.

As shown in Figure 7 (a), the voltage $U_{1}$ and current $I_{1}$ of the photovoltaic array output is measured, and the voltage $U_{\max }$ corresponding to the maximum power under the current illumination and temperature is obtained by the maximum power point tracking (MPPT) algorithm. The $U_{\max }$ and $U_{1}$ are compared, and the differential input PI controller is used for pulse width modulation (PWM). The modulation signal $g_{1}$ is transmitted to the switch in the Boost circuit to track the maximum power point. The progress of phase locked loop (PLL) and dq transformation of grid voltage and current is the three-phase voltage $U_{\mathrm{g}}$ abc and three-phase current $I_{\mathrm{g} \_ \text {abc }}$ of the grid are detected at the low voltage side of the $10 \mathrm{kV} / 0.38$ $\mathrm{kV}$ transformer. The signal output by $U_{\mathrm{g} a \mathrm{abc}}$ through PLL is used as the phase angle of the $\mathrm{d}$ axis in the dq synchronous rotating coordinate system. The three-phase voltage and threephase current are transformed by abc/dq to obtain $U_{\mathrm{gd}, \mathrm{q}}$ and $I_{\mathrm{gd}, \mathrm{q}}$.

The PV grid connection strategy is shown as Fig.7(b), the given value of DC capacitor voltage $U_{\text {dc_ref }}$ is compared with the measured value $U_{\text {dc. }}$. The reference value $U_{\text {gd_ref }}$ of $d$ axis component of grid-connected current is obtained by PI controller. The voltage uncoupling phase $U_{\mathrm{cd}}$ and $U_{\mathrm{cq}}$ of inverter are obtained by PI controller of current control inner loop. The command voltage $U_{\text {cd_ref }}$ and $U_{\text {cq_ef }}$ are obtained by (6) calculation. The 
modulation signal of inverter is obtained by coordinate transformation and space vector pulse width modulation (SVPWM) generator to control the photovoltaic system connected $\operatorname{grid}^{[8]}$.

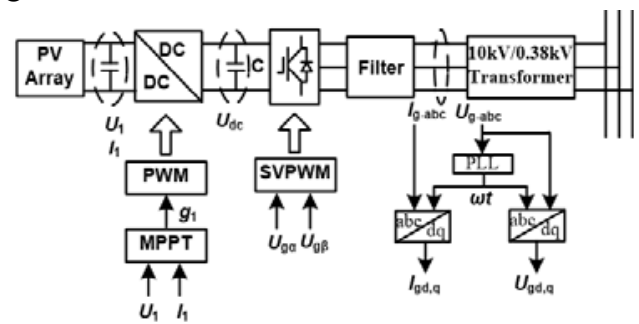

(a) PV grid-connected structure diagram

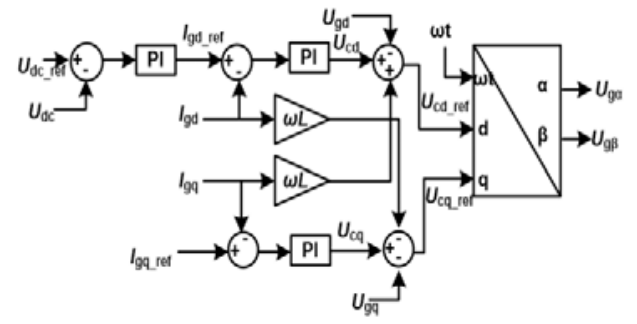

(b) PV grid connection strategy

Fig. 7. Grid connected photovoltaic control.

$$
\left\{\begin{array}{l}
U_{\text {cd_ref }}=U_{\text {cd }}+I_{\mathrm{gd}} \omega L-U_{\mathrm{gd}} \\
U_{\text {cq_ref }}=U_{\mathrm{cq}}-I_{\mathrm{gd}} \omega L-U_{\mathrm{gd}}
\end{array}\right.
$$

The grid-connected strategy of energy storage is similar to the photovoltaic principle. The difference is that direct power control is adopted in the grid-connected strategy of energy storage. The reference values of dq axis component of grid-connected current $U_{\mathrm{gd}}$ ref and $U_{\mathrm{gq} \text { ref }}$ are calculated by active power and reactive power ${ }^{[9]}$. Both DFIG and PMSG wind turbine need variable pitch control and maximum power tracking control. It's necessary to control the machine-side converter and grid-side converter to realize gridconnected. Compared with the control strategy of the above photovoltaic system, the control strategies of DFIG and PMSG wind turbine are more complex, but the general idea remains unchanged ${ }^{[10-12]}$.

\section{Simulation}

The simulation model of traditional medium voltage distribution network and DG is built. In order to study the active distribution network, the grid connection of DG is vital. The specific parameters are shown in table 1 .

Table 1. Simulation Parameters.

\begin{tabular}{|c|c|c|}
\hline Items & Unit & Value \\
\hline Network sources voltage & $\mathrm{kV}$ & 110 \\
\hline $110 \mathrm{kV} / 10 \mathrm{kV}$ transformer capacity & $\mathrm{MVA}$ & 40 \\
\hline $10 \mathrm{kV} / 0.4 \mathrm{kV}$ transformer capacity & $\mathrm{kVA}$ & 250 \\
\hline Wire positive sequence resistance & $\Omega / \mathrm{km}$ & 0.103 \\
\hline Wire zero-sequence resistance & $\Omega / \mathrm{km}$ & 0.927 \\
\hline Wire positive sequence inductance & $\mathrm{H} / \mathrm{km}$ & $0.219 \times 10^{-3}$ \\
\hline Wire zero-sequence inductance & $\mathrm{H} / \mathrm{km}$ & $0.988 \times 10^{-3}$ \\
\hline Wire positive sequence capacitance & $\mathrm{F} / \mathrm{km}$ & $0.329 \times 10^{-6}$ \\
\hline Wire zero-sequence capacitance & $\mathrm{F} / \mathrm{km}$ & $0.163 \times 10^{-6}$ \\
\hline Short-circuit resistance of earth connection & $\Omega$ & 0.001 \\
\hline Earth resistance of earth connection & $\Omega$ & 141.88 \\
\hline Capacity of PV system & $\mathrm{MW}$ & 6 \\
\hline Capacity of DFIG wind turbine & $\mathrm{MW}$ & 6 \\
\hline Capacity of PMSG wind turbine & $\mathrm{MW}$ & 2.5 \\
\hline
\end{tabular}




\begin{tabular}{|c|c|c|}
\hline Items & Unit & Value \\
\hline Capacity of energy-storage device & MAh & 2 \\
\hline Earth connection 1 & $\mathrm{km}$ & 2 \\
\hline Earth connection 2 & $\mathrm{km}$ & 2.9 \\
\hline
\end{tabular}

The simulation time is $0.5 \mathrm{~s}$, the single-phase power delivery condition is set to the circuit breaker of A phase is set to connect in $0.1 \mathrm{~s}$. Three-phase power delivery condition is set to the circuit breakers of three-phase are set to connect in $0.1 \mathrm{~s}$. The maximum peak value and RMS of the ground current and earth potential rise closed to the system power supply are detected. The simulation results are shown in Figs.8-9, and the simulation data are shown in table 2 .

It can be seen from table 2 and Fig. 8 that in the neutral point grounding system through small resistance, in the case of single-phase power delivery between the traditional distribution network and the MW-level DG, the maximum peak ground current reaches more than $27 \mathrm{~A}$, the RMS reaches more than $15 \mathrm{~A}$, and the maximum peak earth potential rise reaches more than $3830 \mathrm{~V}$, the RMS reaches more than $2220 \mathrm{~V}$. It can be seen from Table 2, Fig.9 that under the condition of three-phase power delivery, the maximum peak values of the ground current are all below $0.45 \mathrm{~A}$, and the RMS are all below $0.21 \mathrm{~A}$. The maximum peak values of earth potential rise are all below $81.18 \mathrm{~V}$, and the RMS are all below $36 \mathrm{~V}$. It can be seen from Fig. 9 that in the case of three-phase power delivery, the maximum peak value of earth potential rise of the traditional distribution network and the grid which connected the DFIG wind turbine and energy storage device exceeds $50 \mathrm{~V}$, but the duration is less than $0.005 \mathrm{~s}$, and the RMS is less than $36 \mathrm{~V}$. Therefore, it is suggested that device and measures should be taken to convert single-phase power delivery to threephase power delivery in medium-voltage distribution network with neutral point grounding through small resistance to ensure personal safety.
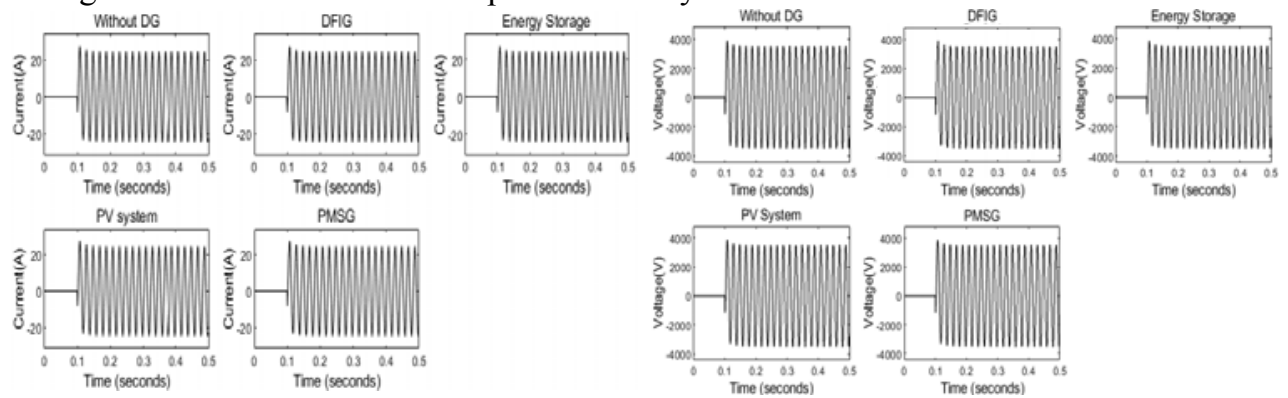

PVSystem.
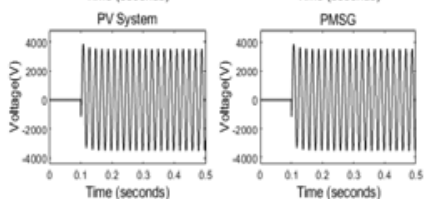

(a)ground current

(b)earth potential rise

Fig. 8. Simulation diagram of single-phase delivery.
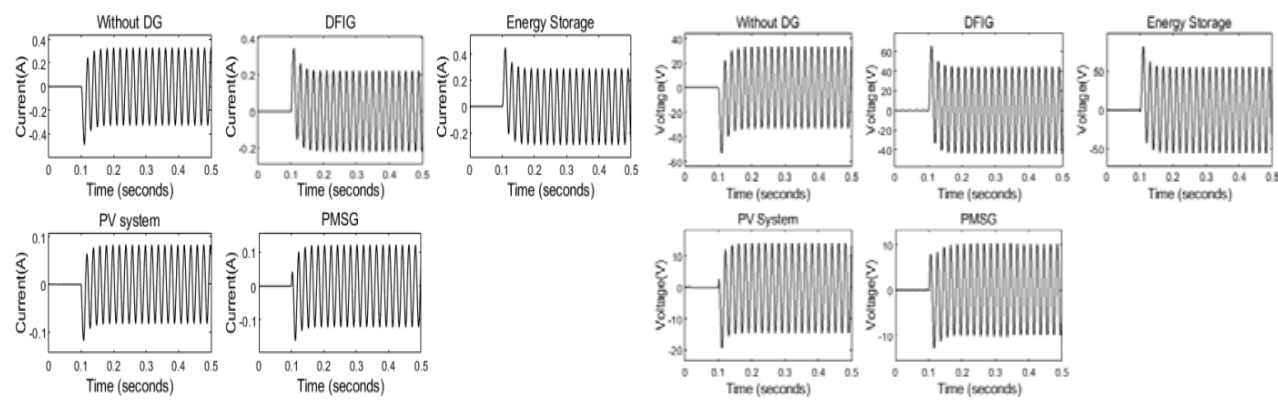

(a)ground current

(b)earth potential rise

Fig. 9. Simulation diagram of three-phase delivery. 
Table 2. Tables of simulation results.

\begin{tabular}{|c|c|c|c|c|c|c|}
\hline \multirow{2}{*}{$\begin{array}{c}\text { DG } \\
\text { type }\end{array}$} & \multirow{2}{*}{$\begin{array}{c}\text { Capacity } \\
\text { (MW) }\end{array}$} & \multirow{2}{*}{$\begin{array}{c}\text { Power } \\
\text { delivery } \\
\text { mode }\end{array}$} & $\begin{array}{c}\text { Maximum } \\
\text { peak value }\end{array}$ & RMS & $\begin{array}{c}\text { Ground current (A) } \\
\text { peak value }\end{array}$ & \multicolumn{2}{c|}{ Earth potential rise (V) } \\
\hline \multirow{2}{*}{ None } & \multirow{2}{*}{0} & Single-phase & 27.40 & 15.70 & 3887.00 & 2227.00 \\
\cline { 3 - 7 } & & Three-phase & 0.33 & 0.21 & 53.21 & 21.50 \\
\hline \multirow{2}{*}{$\begin{array}{c}\text { PV } \\
\text { system }\end{array}$} & \multirow{2}{*}{6} & Single-phase & 27.31 & 15.65 & 3874.00 & 2220.00 \\
\cline { 3 - 7 } & & Three-phase & 0.08 & 0.05 & 14.15 & 9.11 \\
\hline \multirow{2}{*}{ DFIG } & \multirow{2}{*}{6} & Single-phase & 27.42 & 15.72 & 3891.00 & 2230.00 \\
\cline { 3 - 7 } & & Three-phase & 0.34 & 0.14 & 65.78 & 28.51 \\
\hline \multirow{2}{*}{ PMSG } & \multirow{2}{*}{2.5} & Single-phase & 27.41 & 15.71 & 3889.00 & 2229.00 \\
\cline { 3 - 7 } & & Three-phase & 0.21 & 0.13 & 31.28 & 18.19 \\
\hline \multirow{2}{*}{$\begin{array}{c}\text { Energy- } \\
\text { storage }\end{array}$} & \multirow{2}{*}{1} & Single-phase & 27.01 & 15.50 & 3831.00 & 2199.00 \\
\cline { 3 - 7 } & Three-phase & 0.45 & 0.19 & 81.18 & 35.31 \\
\hline
\end{tabular}

As shown in table 2, it is found that under the condition of single-phase power delivery, the difference between the simulation value of the distribution network connected with DG and the traditional distribution network is very small, and the compared values under threephase power delivery are much greater obviously. It's meaningful to calculate the compared value.

The formula of compared value is as follows:

$$
C=\frac{D-T}{T}
$$

$\mathrm{C}$ is compared value of simulation value between traditional distribution network and distribution network connected DG, the unit is \%; D is the simulation value of distribution network connected DG; $\mathrm{T}$ is the simulation value of traditional distribution network.

As shown in table 3, even if the three-phase delivery device is adapted in the neutral point grounding system through small resistance, the ground current and earth potential rise may increase and it will still pose a threat to personal safety.

Table 3. The Compared Value of Simulation Results under Three-phase Delivery Tables of Simulation Results.

\begin{tabular}{|c|c|c|c|c|}
\hline \multirow{2}{*}{ DG type } & \multicolumn{2}{|c|}{$\begin{array}{c}\text { Compared Value of } \\
\text { Ground Current (\%) }\end{array}$} & \multicolumn{2}{c|}{$\begin{array}{c}\text { Compared Value of } \\
\text { Earth Potential Rise (\%) }\end{array}$} \\
\cline { 2 - 5 } & $\begin{array}{c}\text { Maximum } \\
\text { peak value }\end{array}$ & RMS & $\begin{array}{c}\text { Maximum } \\
\text { peak value }\end{array}$ & RMS \\
\hline PV system & -75.76 & -76.19 & -73.41 & -57.63 \\
\hline DFIG & 3.03 & -33.33 & 23.62 & 32.60 \\
\hline PMSG & -36.36 & -38.10 & 41.21 & -15.40 \\
\hline Energy-storage & 36.36 & -9.52 & 52.57 & 64.23 \\
\hline
\end{tabular}

\section{Conclusion}

The safety operation of $10 \mathrm{kV}$ distribution network with neutral point grounding through small resistance is studied in this paper. The main purpose is to study the situation of power mis-delivery after installing the connection of earth connection of maintenance point in the operation of maintenance personnel. The research shows that whether it is the traditional or active distribution network with MW-level distributed power supply, the ground current and earth potential rise are far beyond the range that the human body can withstand when 
the single-phase power is delivered by mistake. Compared with the single-phase power delivery, the three-phase power delivery has obvious advantages and can guarantee the safety of the human body. Therefore, it is recommended that device and measures should be taken to convert single-phase power delivery to three-phase power delivery in distribution network with neutral point grounding through small resistance. However, under three-phase power delivery conditions, the impact of DG access in distribution network is relatively large, especially for the increase of ground current and earth potential rise, it is still possible to pose a threat to personal safety, which needs further research.

\section{Acknowledgements}

This work is supported by Science and Technology Program of State Grid Corporation of China (No.5213302000G1).

\section{References}

1. J. WangZ. Hu and S. Xie, Expansion planning model of multi-energy system with the integration of active distribution network, APPL ENERG, 253, 113517 (2019)

2. J.H. YiR. Cherkaoui and M. Paolone, Dispatch-aware planning of energy storage systems in active distribution network, ELECTR POW SYST RES, 190, 106644 (2021)

3. N. Yan, H. Zhao, T. Yan and S. Ma, Research on capacity configuration method of energy storage system in active distribution network considering the assessment of health risk for retired electric vehicle batteries, Energy Reports, 6, 1106-1113 (2020)

4. H. Wu, S. Wang, B. Zhao, and C. Zhu, Energy management and control strategy of a grid-connected PV/battery system, Int. Trans. Electr. Energy Syst, 25, 1590-1602 (2014)

5. B. Yang, Y. Hu, H. Huang, H. Shu, T. Yu and L. Jiang, Perturbation estimation based robust state feedback control for grid connected DFIG wind energy conversion system, Int. J. Hydrogen Energ, 42, 20994-21005 (2017)

6. A.H. Kasem Alaboudy, A.A. Daoud, S.S. Desouky and A.A. Salem, Converter controls and flicker study of PMSG-based grid connected wind turbines, Ain Shams Engineering Journal, 4, 75-91 (2013)

7. A. Hu, J. Zhuang, Y. Tao, J. Yang and C. Zhou, A Voltage Sag Suppression Method With Short Response Time Based On Energy Storage System, Proc. CIEEC, 18541859 (2019)

8. A. RaviP.S. Manoharan and J. Vijay Anand, Modeling and simulation of three phase multilevel inverter for grid connected photovoltaic systems, Sol. Energy, 85, 28112818 (2011)

9. A. Colmenar-Santos, A. Linares-Mena, J.F. Velázquez and D. Borge-Diez, Energyefficient three-phase bidirectional converter for grid-connected storage applications, Energ. Convers. Manage, 127,599-611 (2016)

10. J. Hu and Y. He, Modeling and enhanced control of DFIG under unbalanced grid voltage conditions, Electr. Pow. Syst. Res, 79, 273-281 (2009)

11. L. FanH. Yin and Z. Miao, A novel control scheme for DFIG-based wind energy systems under unbalanced grid conditions, Electr. Pow. Syst. Res, 81, 254-262 (2011)

12. X. Zeng, H. Zhang, Y. Li, Y. Yang, and X. Yang, Low Voltage Ride Through Control of Large Direct-drive Wind Turbine with Multiphase PMSG and Hybrid Three-level Full-size Converters, Automation of Electric Power Sys, 36, 23-29 (2012) 